\title{
Unilateral Capecitabine-related Hand-foot Syndrome
}

\author{
Shuntaro Matsuda ${ }^{1}$, Hideki Koketsu ${ }^{2}$, Manabu Hayakawa ${ }^{1}$ and Naoto Nagata ${ }^{1}$
}

Key words: hand-foot syndrome, capecitabine, hemiplegia

(Intern Med 54: 2779, 2015)

(DOI: 10.2169/internalmedicine.54.4920)

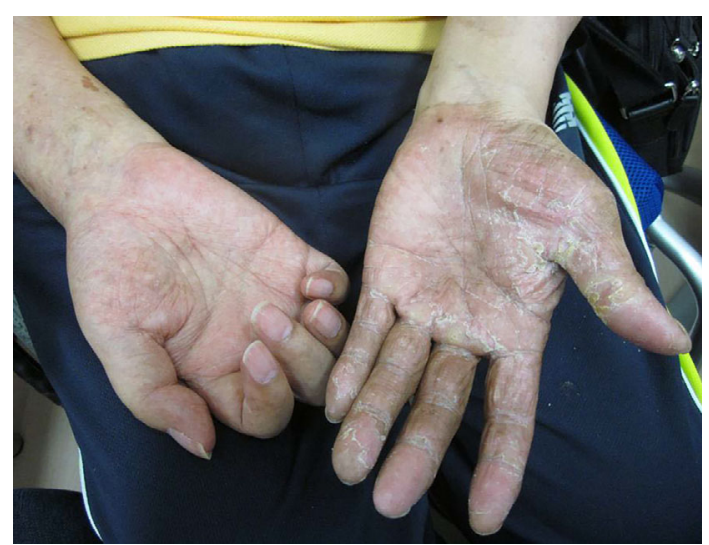

Picture 1.

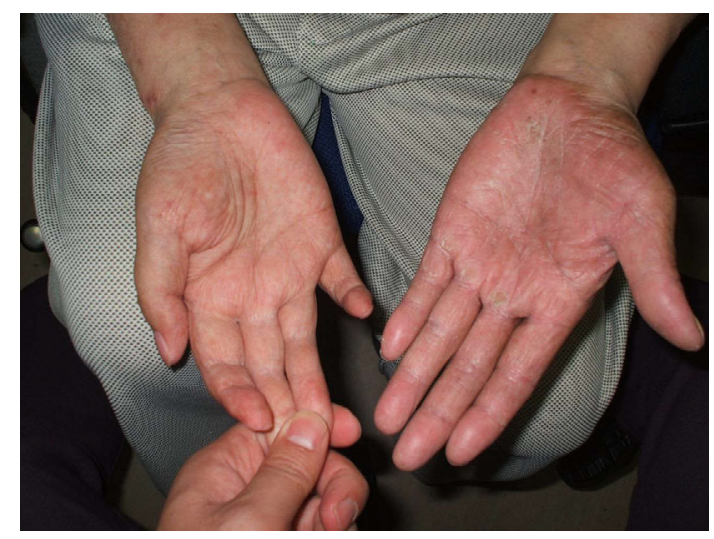

Picture 2.
A 60-year-old man with a history of cerebral infarction presented at our hospital. He was subsequently diagnosed to have multiple liver metastases of advanced descending colon cancer, based on the findings of computed tomography. His physical examination showed hemiplegia of the right upper and lower limbs. He was treated with palliative chemotherapy, consisting of capecitabine, oxaliplatin (XELOX), and bevasizumab. After two cycles of this chemotherapy, handfoot syndrome (HFS) prominently developed in the palm of his left hand (Picture 1). HFS remained for seven days after the onset of symptoms (Picture 2). HFS is the most common toxicity of capecitabine related to the tissue-specific expression of drug-metabolizing enzymes and it is usually seen in both the hands and the feet (1). To our knowledge, this is only the second case of capecitabine-induced unilateral HFS to be reported (2). This report suggests that HFS is strongly linked to the mechanical disturbance of daily life and it may also influence the onset of long-term paralysis.

The authors state that they have no Conflict of Interest (COI).

\section{References}

1. Milano G, Etienne-Grimaldi MC, Mari M, et al. Candidate mechanisms for capecitabine-related hand-foot syndrome. $\mathrm{Br} \mathrm{J}$ Clin Pharmacol 66: 88-95, 2008.

2. Almeida da Cruz L, Hoff PM, Ferrari CL, Riechelmann RS. Unilateral hand-foot syndrome: does it take sides? Case report and literature review. Clin Colorectal Cancer 11: 82-84, 2012.

\footnotetext{
${ }^{1}$ Department of Community and General Medicine, Faculty of Medicine, University of Miyazaki, Japan and ${ }^{2}$ Department of Dermatology, Faculty of Medicine, University of Miyazaki, Japan

Received for publication January 13, 2015; Accepted for publication March 3, 2015

Correspondence to Dr. Shuntaro Matsuda, bzh15353@med.miyazaki-u.ac.jp

(C) 2015 The Japanese Society of Internal Medicine Journal Website: http://www.naika.or.jp/imonline/index.html
} 